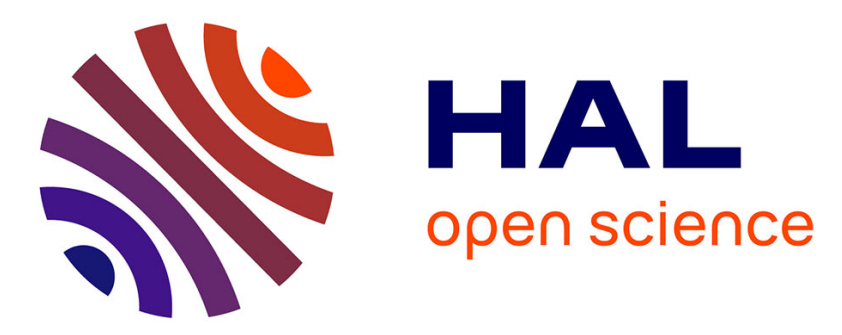

\title{
Concentrations and seasonal cycle of black carbon in aerosol at a coastal Antarctic station
}

\author{
Eric Wolff, Hélène Cachier
}

\section{To cite this version:}

Eric Wolff, Hélène Cachier. Concentrations and seasonal cycle of black carbon in aerosol at a coastal Antarctic station. Journal of Geophysical Research: Atmospheres, 1998, 103 (D9), pp.11033-11041. 10.1029/97JD01363 . hal-03119738

\section{HAL Id: hal-03119738 \\ https://hal.science/hal-03119738}

Submitted on 25 Jan 2021

HAL is a multi-disciplinary open access archive for the deposit and dissemination of scientific research documents, whether they are published or not. The documents may come from teaching and research institutions in France or abroad, or from public or private research centers.
L'archive ouverte pluridisciplinaire HAL, est destinée au dépôt et à la diffusion de documents scientifiques de niveau recherche, publiés ou non, émanant des établissements d'enseignement et de recherche français ou étrangers, des laboratoires publics ou privés. 


\title{
Concentrations and seasonal cycle of black carbon in aerosol at a coastal Antarctic station
}

\author{
Eric W. Wolff \\ British Antarctic Survey, Cambridge, England \\ Hélène Cachier \\ Centre des Faibles Radioactivites, Laboratoire Mixte CNRS-Commissariar à l'Energie Atomique, Gif sur Yvette, France
}

\begin{abstract}
Aerosol black carbon concentrations have been measured between 1992 and 1995 at Halley station using an aethalometer. The complete record is dominated by a number of events of high concentration that are clearly due to contamination from the station generators. However, using detailed meteorological data, it is possible rather satisfactorily to remove these events from the record. The events can be used to show that local contamination has no significant effect on sulfate or other major ion data. The remaining data then show a clear seasonal cycle, with monthly mean values of $0.3-2 \mathrm{ng} \mathrm{m}^{-3}$, slightly higher than those recorded at south pole. The cycle peaks in summer, with a possible doublet, and an overall maximum in October. This pattern is similar to that of south pole and of mineral dust at the coastal Neumayer station. The pattern seems to be controlled by the timing of biomass burning in the tropics, strongly modulated by the efficiency of transport to Antarctica. This transport seems to be poorly represented in model simulations. The concentrations are too low to have any significant effect on snow albedo. The similarity of the Halley and south pole data suggest that ice cores should give a historical record of black carbon that is rather representative of the Antarctic as a whole and therefore indicative of trends in biomass burning throughout the southern hemisphere.
\end{abstract}

\section{Introduction}

Carbonaceous aerosol in the troposphere has three main sources: natural primary and secondary emissions of organic gases from vegetation, combustion of fossil fuels, and combustion of vegetation (biomass burning). Estimates of annual fluxes from these sources suggest that the latter two, which are both predominantly under anthropogenic control, dominate the global budget of carbonaceous aerosol [Cachier, 1995]. The major source regions are the tropical regions for biomass burning and the temperate latitudes of the northern hemisphere for industrial combustion.

In urban areas, the detailed chemical makeup of the carbon fraction of aerosol is of particular interest. Measurements in remote areas can be used to trace the extent of pollution reaching these regions. The effect of carbonaceous aerosol on radiative properties of the atmosphere is of potential climatic importance and requires study. In the polar regions, the effect on the albedo of snow surfaces has also been studied [Warren and Clarke, 1990]. Finally, the possibility of using ice cores to study past variations in combustion is very attractive, and studies have recently been started [Chylek et al., 1992; Cachier, 1995; Legrand et al., 1995].

The carbonaceous aerosol includes many different chemical forms, with a very high carbon content as their common factor. They are often divided into two main groups: organic carbon and black (or soot) carbon. Black carbon (BC), although generally the minority part of carbonaceous aerosol, is often measured because of the relative simplicity of the measurement. It is defined operationally through its high degree of optical absorption or its refractory behavior [Cachier, 1995]. Because of its resistance to

Copyright 1998 by the American Geophysical Union.

Paper number 97JD01363.

0148-0227/98/97JD-01363\$09.00 atmospheric attack and its capability to be transported away from source regions, it may serve as an unambiguous tracer of combustion.

Black carbon has been measured in air at Halley station (75 35'S, 26 14'W), Antarctica, since February 1992 using an aethalometer. This has provided data at 2 hour intervals. Owing to the relative proximity of station generators, careful contamination control is required in order to use the data to study background black carbon. This paper describes the procedure for doing this and discusses the seasonal and interannual variability of black carbon at Halley in terms of source strengths and transport efficiencies.

\section{Site Description and Sampling Method}

Aethalometer measurements have been made at Halley 5 station since February 1992. The station consists of three main aboveground buildings on the Brunt Ice Shelf, approximately 15 $\mathrm{km}$ from the sea [Wolff et al., this issue (a)]. There are two generators at the station, and these are the main local source of combustion. In the past, there have been occasional instances of waste buming, and vehicles provide smaller sources of combustion. There are no other stations within $300 \mathrm{~km}$ of Halley.

The aethalometer inlet is situated $12 \mathrm{~m}$ south of the building known as the ICB (Figure 1). The inlet consists of a tube situated in an upturned jar intended to deter the buildup of blowing snow on the inlet. Although the operators report some buildup of rime around the tube, it does not affect air flow, and the flexibility of the system causes the rime to be removed in moderate winds. We therefore do not expect it to cause a significant loss of black carbon (especially as (see later) we select against periods with low wind speeds). Air is sucked through a semirigid plastic tube to a filter in the aethalometer, which is situated inside the building. The flow rate of air is generally in the range $25-35 \mathrm{~L} / \mathrm{min}$, except during the period October-December 1994 when the pump was faulty, and 


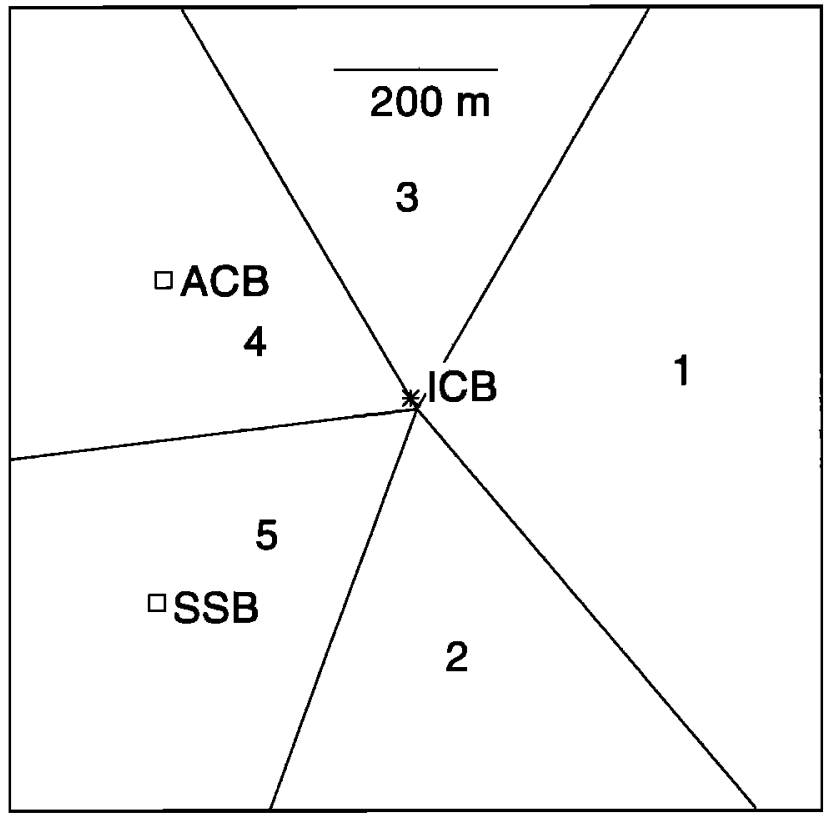

Figure 1. Directional plan of the Halley station site. The center point is the aethalometer location. The asterisk marks the Ice and Climate Building (ICB). The Accommodation Building (ACB) and Space Science Building (SSB) both have generators. The sectors 1 to 5 are the direction bins for selecting data (see text). North is upward.

flow rates eventually fell as low as $12 \mathrm{~L} / \mathrm{min}$ before the pump was replaced. The collection substrate used has been a cellulose $47 \mathrm{~mm}$ Pallflex filter, except during December 1994, when quartz filters were used. The aethalometer is calibrated for each type of filter, but the possibility of some bias during the period with quartz filters must exist.

The principle of the aethalometer is that the attenuation of light from a light beam passing through the filter is measured. Light absorption is enhanced by multiple reflections inside the fibrous filter matrix. The difference in attenuation from one reading to the next can be used to estimate the black carbon accumulated on the filter during the measurement interval and hence the concentration of black carbon in the air. This method assumes that BC particles form the only aerosol component which significantly absorbs light. It also effectively defines black carbon solely by its light-absorbing properties. It involves an assumption that the light-absorbing properties of the measured $\mathrm{BC}$ aerosol are the same as those of the calibration material used at the manufacturers, an assumption that is unlikely to be true. Indeed, BC particle shape and surface coating are likely to vary with the origin and aging of the aerosols thus modifying their absorption capability [Chylek et al., 1995]. The attenuation cross section can vary by a factor of 3 from that used in the calibration, with remote $\mathrm{BC}$ aerosols having on average particularly low values (implying that concentrations from the aethalometer are lower than the true values) [Liousse et al., 1993]. However, owing to the lack of consensus, the aethalometer average calibration coefficient recommended for this filter type $\left(14 \mathrm{~m}^{2} \mathrm{~g}^{-1}\right)$ has been retained.

Filters are removed when the light attenuation reaches a predefined value which for remote sites is set at 80-100. When quartz filters are used, they can in principle be examined to determine the type of carbonaceous aerosol present. Unfortunately, as discussed later, at Halley, most filters can continue for a considerable time with low attenuation values but then experience one or more episodes of pollution from the station generators.
Although such episodes can be removed from the aethalometer time series (as discussed later), they overwhelm the eventual composition of the carbon on the filters. The filters therefore generally represent very local combustion sources and cannot be used to characterize the chemistry of the background carbonaceous aerosol.

It is important to extend the sampling interval such that a significant change in the optical attenuation of the filter is achieved. A 2-hour interval was used throughout and gave generally positive values. During June-August 1993, a faulty lamp led to considerable noise in the measurements, and these data have been smoothed or omitted from data analyses, as appropriate.

Station vehicles were kept well clear of the aethalometer inlet, except on a few occasions when maintenance necessitated a closer approach. Such brief intervals seemed to have no effect on the data. A simple test suggested that at moderate wind speeds, a snowmobile parked with its engine running could be detected only when it approached to within a few meters of the aethalometer inlet. The main local pollution effects come from the two station generators, located on the buildings known as the ACB and SSB, respectively (Figure 1). Station personnel report that on some occasions, black particles from these generators (at 350 and $400 \mathrm{~m}$ from the aethalometer inlet, Figure 1) can be seen on the snow surface, and the aethalometer readings increase dramatically. Although the predominant easterly wind direction at Halley is such that the generators are downwind of the aethalometer, it is also often westerly, so that they are upwind [König-Langlo et al., this issue; Wolff et al., this issue (a)]. In the next section, we discuss our method for filtering pollution events from our data and also comment on the use of the aethalometer as an indicator of pollution that can be used to assess the importance of local sources for other chemical species.

\section{Data and Meteorological Filtering}

The entire data set (Figure 2) is dominated by very large spikes in black carbon, often of several hundred $\mathrm{ng} \mathrm{m}^{-3}$, as compared to background values frequently at below $1 \mathrm{ng} \mathrm{m}^{-3}$. These spikes are clearly associated with winds blowing from the station generators toward the aethalometer inlet.

To confirm this, and to allow filtering of the data, the 2 hour aethalometer data have been classed according to the wind speed and direction for the same period. These meteorological data are available as $5 \mathrm{~min}$ averaged values, giving a total of 24 readings for



Figure 2. Unfiltered black carbon (BC) data from the Halley aethalometer. The record is dominated by large spikes. The area of negative values in mid 1993 is due to noise when the lamp was faulty, and the area in late 1994 is where the pump flow rates were low. 

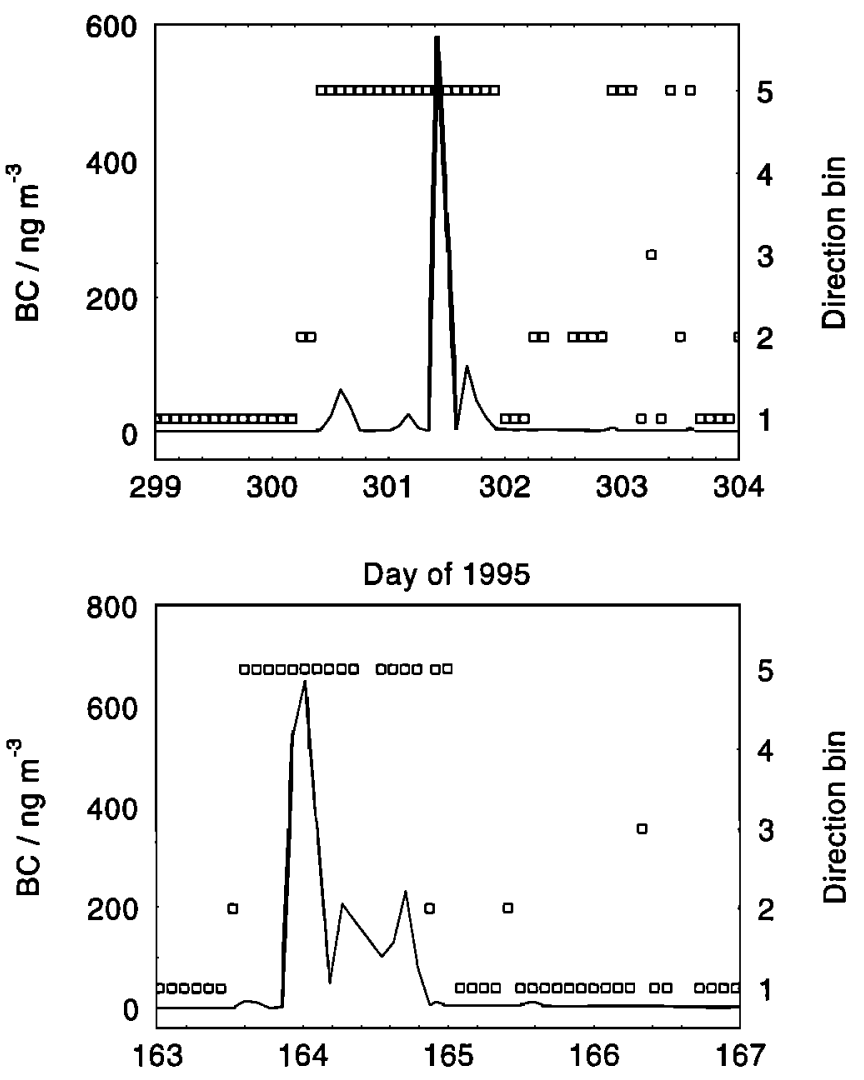

Day of 1992

Figure 3. Raw black carbon (BC) data for two contamination events. The squares show the wind direction bin assigned to each 2-hour period. The contamination events are confined to periods when the wind is from the sectors where the generators are.

each aethalometer reading. Each 5 min value has been classed according to the wind direction, speed, and any problems with the data (such as negative or overrange speeds). The wind direction bins are (1) $030^{\circ}-140^{\circ}$, (2) $140^{\circ}-200^{\circ}$, (3) $330^{\circ}-030^{\circ}$, (4) $265^{\circ}$ $330^{\circ}$, and (5) $200^{\circ}-265^{\circ}$. Direction bins 4 and 5 are centred on buildings with generators (Figure 1). The speed bins are $>5$ knots $\left(>2.6 \mathrm{~m} \mathrm{~s}^{-1} ; 1\right), 2-5$ knots $\left(1.0-2.6 \mathrm{~m} \mathrm{~s}^{-1} ; 2\right), 1-2$ knots $(0.5-1.0 \mathrm{~m}$ $\left.\mathrm{s}^{-1} ; 3\right)$, and $<1 \mathrm{knot}\left(<0.5 \mathrm{~m} \mathrm{~s}^{-1}, 4\right)$. Higher numbers indicate conditions more likely to lead to contamination. Within a 2 hour period, the aethalometer data are assigned the highest direction and speed codes of the 24 meteorological readings. Thus the direction code 4 assigned to an aethalometer reading means that the wind was from the sector $265^{\circ}-330^{\circ}$ for at least one $5 \mathrm{~min}$ period during the aethalometer data interval.

\subsection{Local Contamination}

Figure 3 shows the data and the assigned direction codes for two different episodes of local pollution and clearly indicates the dominant effect of wind direction. This feature allows us to use the black carbon data to investigate the effect of local pollution on other chemical species. In Figure 4, we show daily sulfate aerosol concentrations for two periods of particularly strong local pollution. The winter section shown in the lower panel includes some of the highest $\mathrm{BC}$ concentrations recorded in the 4 year record, yet sulfate appears unperturbed (within an uncertainty of about $5 \mathrm{ng} \mathrm{m}^{-3}$ ). The autumn section (upper panel) confirms that there is no noticeable perturbation for large BC events when sunlight is present and $\mathrm{SO}_{2}$ oxidation might be faster. A similar lack of perturbation can be found for chloride. These results indicate the minimal effect on sulfate and chloride even during huge pollution spikes and suggest that no corrections are needed to these data. This shows the value of the aethalometer as a very specific indicator of pollution events.

At Dumont d'Urville, a similar technique, using visible observation of grayness on filters as an indicator of pollution events, was used to eliminate a small number of aerosol filters from the major ion data set obtained there [Wolff et al., this issue (b)]. At Halley, visibly gray major ion aerosol filters were never observed (J. S. Hall, personal communication, 1996). Given that even the dark gray filters at Dumont d'Urville led to an increase of only 50 $100 \mathrm{ng} \mathrm{m}^{-3}$ in sulfate, and given the much closer situation of the filters there to generators than at Halley and the larger volumes pumped through each filter at Dumont d'Urville, the two sets of findings appear compatible.

It is interesting to note the extremely low particulate sulfur/BC ratio that can be deduced for local contamination from Halley ( $<1 \%$ compared to $20 \%$ for urban areas [Cachier, 1995]). This may to some extent be a result of minimal oxidation of $\mathrm{SO}_{2}$ by the time the air from the generators reaches the filters. Nonetheless, these results suggest that only a very small area, of order $200 \mathrm{~m}$ or less, around moderate-sized Antarctic stations is excluded for aerosol monitoring for sulfate (and less sensitive species).

\subsection{Filtering the Dataset}

Returning to the BC data alone, in order to make the most conservative possible filtering of the data to exclude local
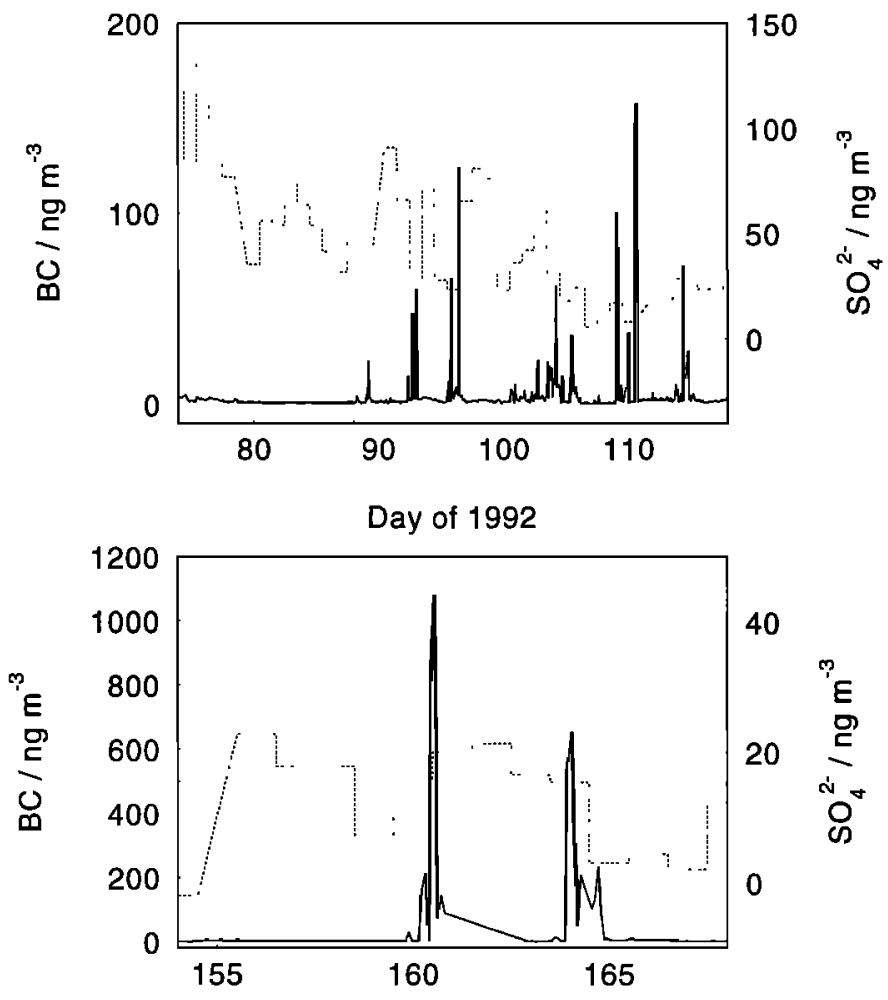

Day of 1992

Figure 4. Raw black carbon (BC) data (solid lines, left axis) and daily aerosol sulfate concentrations (dashed line, right axis) for two periods in 1992. The top section is from the autumn period, when non-sea-salt sulfate is still elevated, while the lower section is from winter. 


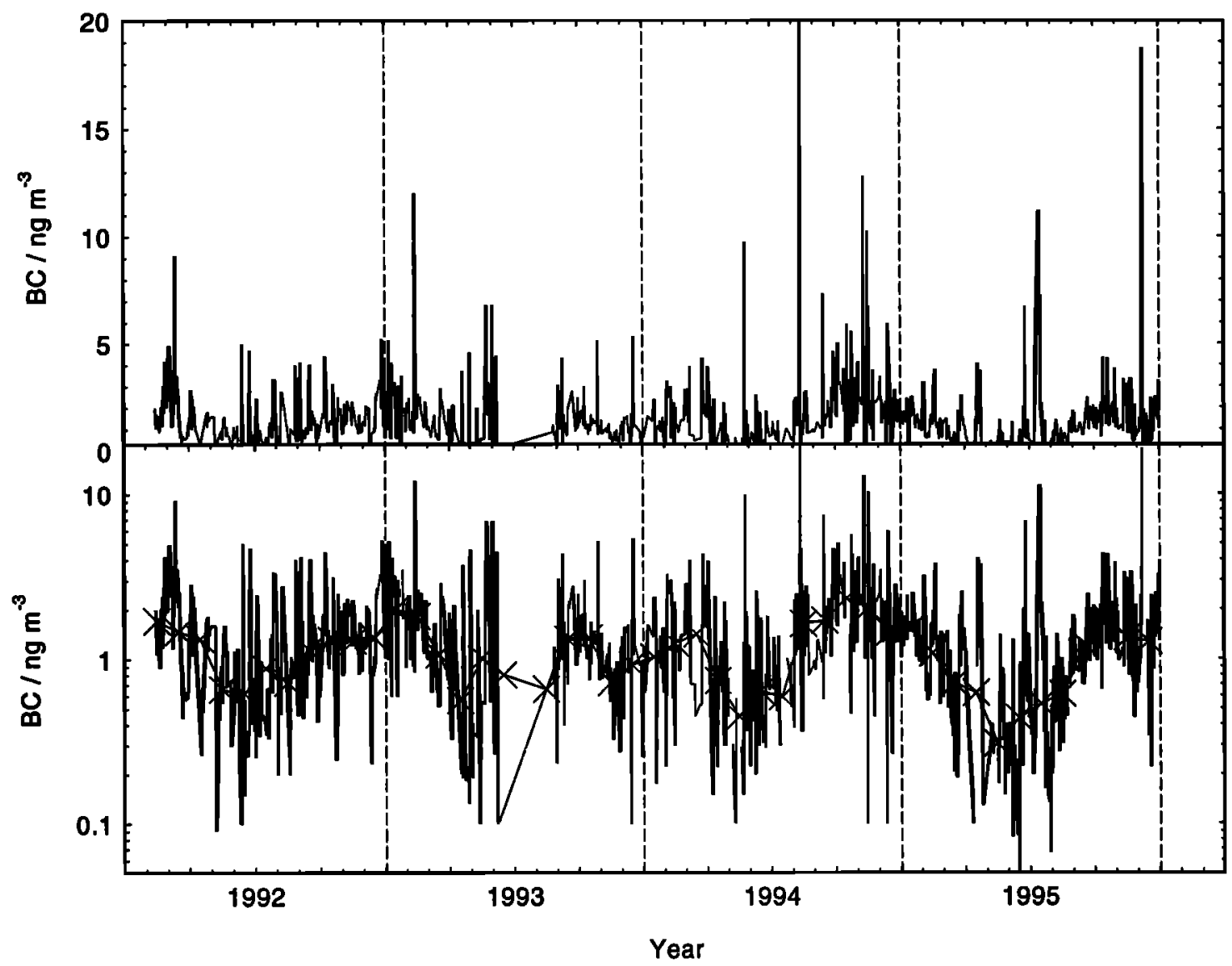

Figure 5. Daily means of black carbon $(\mathrm{BC})$ data, filtered as described in the text to remove local contamination. Data are shown on linear and logarithmic scales. The crosses drawn through the logarithmic data are the monthly logarithmic means of the daily values. A linear average looks very similar. Data from July 1993 are missing because of the noisy lamp at that time.

pollution, we have accepted only those data in both direction and speed bins 1 . This amounts to approximately $48 \%$ of the datapoints over the 4-year period. This method ensures that we exclude data where the wind was from the direction of a generator even for a brief period during the 2 hour interval. This should also more or less exclude the possibility of including times when pollution has traveled away from the aethalometer after emission and then back toward it later. It also excludes times when low wind speeds could have allowed pollution to drift slowly upwind. The disadvantage of the method is that it reduces our data set to one with particular conditions which could be untypical for the background aerosol (for instance, if the background aerosol is different for westerly and easterly winds). The fact that we include nearly $50 \%$ of datapoints means that the data set should not be too heavily biased. Although the percent retained naturally varies from month to month (with between 20 and $65 \%$ retained), over the 4 year period there is no evidence of a seasonality in retention of data.

As a final check on the representative nature of our final data set, we examined the rejected data that we could have used from the 1995 data set. Although they comprise a relatively small number of datapoints, the data in speed bin 2 (i.e., 2-5 knots) show the same seasonality as the accepted data, and no obvious pollution spikes are included. Very few of the 1995 data were rejected because they had speeds lower than 2 knots. The relatively few datapoints in direction bins 2 and 3 also contain no obvious pollution spikes and show a seasonality consistent with that of the accepted data. Only in the two direction bins coming from the generators are large pollution spikes seen and dominant. These findings imply that our selection criteria is more stringent than necessary and that we could safely relax both the speed and direction criteria. On the other hand, our criteria appear not to have biased the data in any significant way, although we have of course rejected all data during westerly winds. Since widening the speed and direction bins adds relatively few datapoints, we prefer to keep to our stringent selection criteria. The finding that the aerosol BC concentration is increased by a factor more than 100 over background when the sampler finds itself downwind of the station at a few hundred meters, but is not increased at all when it is the same distance upwind is consistent with the findings of surface snow analyses at south pole [Warren and Clarke, 1990].

\section{Filtered Black Carbon Data Set at Halley}

The data set, filtered as described above, has values for 2-hour samples ranging from 0 to about $20 \mathrm{ng} \mathrm{m}^{-3}$, excluding a few negative values ( $<3 \%$ of all values after filtering) and a few larger outliers. Concentrations may vary by up to 1 order of magnitude within short periods between 2-hourly data values. Far from source regions, such a varibility may be explained only by abrupt incursions of (relatively) polluted air masses originating from lower latitudes. The negative values are mainly very small and indicate only that we are working close to the detection limit for our instrument. This could be improved by sampling for longer periods 
but at the expense of resolution. The daily averages are shown in Figure 5 for the 4-year period. As expected, the concentrations at Halley are, with the exception of south pole, lower than those recorded elsewhere on Earth (even if the values are increased at Halley and south pole by a factor 3 to allow for possible variations in the attenuation cross section for black carbon [Liousse et al., 1993]).

\subsection{Seasonal Cycle of Black Carbon}

A clear seasonal cycle emerges from the daily values, with an autumn/winter minimum (values mainly in the range 0.1-1.0 $\mathrm{ng} \mathrm{\textrm {m } ^ { - 3 }}$ ) and a summer maximum (values mainly in the range 0.5 $5.0 \mathrm{ng} \mathrm{m}^{-3}$ ). No significant interannual variability is observed in the 4 years' data so far.

The seasonal pattern is seen in the monthly means plotted in Figure 5. The means were calculated as a logarithmic average, but a very similar pattern was seen when linear averages or medians were used. In each year, a minimum is seen in the April-June period, and a maximum is seen in the summer period. When the 4year average is taken (Figure 6), the minimum is in May, while two maxima are seen in October and January. It is not clear whether this is a real double maximum or is the result of averaging a maximum whose timing differed in each of the 4 years. A true double maximum was observed in 1 year (1993/1994), and signs of it are present in other years.

The seasonal cycle of $\mathbf{B C}$ at Halley can be compared with that obtained at south pole [Hansen et al., 1988; Bodhaine, 1995]. An aethalometer was used there also, but with quartz rather than cellulose filters. At both stations, the manufacturers' calibration has been used, so the results should be comparable, even though the absolute values of black carbon may be higher than we both report (see above). The seasonal variation at the two stations (Figure 6) is remarkably similar (the south pole values are for 1 year only; although a similar pattern was observed in the following 2 years also, missing data precluded the calculation of monthly medians for the other years [Bodhaine, 1995]). BC concentrations at Halley are about a factor 2 higher in winter than at south pole, with a rather smaller factor in summer. This comparison result has, however, to be presented carefully as the data treatment may significantly influence low level mean concentrations. Indeed, if the negative values obtained in our $\mathrm{BC}$ record were not discarded (attenuation being recalculated for a longer time base), we would have calculated somewhat smaller values especially for the winter period when concentrations are lowest and close to the detection limit of the instrument. Thus the difference between the two data sets would have been reduced.

This agreement between a coastal and an inland station provides support for the cycle seen, overcoming any doubts about the correction procedures used at each station. It also suggests that both stations are responding almost identically to a common source. Although it would be desirable to see a record from a third site, preferably on the Pacific or Indian Ocean sector of Antarctica, the implication is that each station has a signal that can be considered representative for the whole Antarctic continent. This in turn implies that ice core records of BC from Antarctica can be expected to have a wide geographical significance.

BC particulate concentrations are expected to reflect primarily variations of source intensity and transport patterns, although enroute scavenging of particles may also be an important determinant. All these parameters are likely to have a repetitive seasonal dependence which will account for the $\mathrm{BC}$ seasonal cycle over Antarctica.

4.1.1. Meteorological transport to Antarctica. The seasonal cycle of BC can be compared with the records of other species at Halley and at other coastal stations [Artaxo et al., 1992; Jaenicke

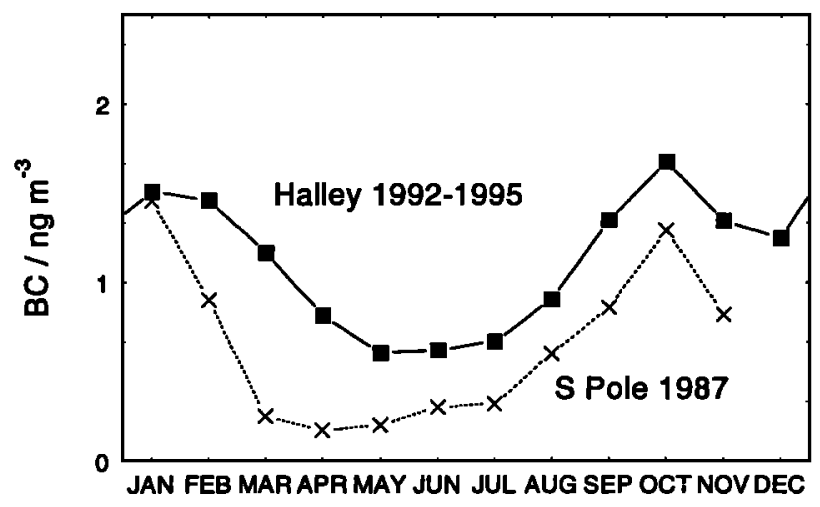

Figure 6. Four-year averaged seasonal cycle (based on the monthly logarithmic means of Figure 5) of BC at Halley (solid line). The dashed line is the monthly medians for 1987 from south pole [Bodhaine, 1995].

et al., 1992; Wagenbach, 1996; Minikin et al., this issue; Wagenbach et al., this issue]. These include species assumed to be mainly of continental origin, and most of them display a pronounced concentration maximum in summer. The most obvious similarity is with the mineral dust record from Neumayer station [Wagenbach, 1996] (no mineral dust data are available for Halley). This shows peaks in November and February, a minimum in May, and a summer/winter ratio of about 3 . Furthermore, dust concentrations at Neumayer are also slightly higher than dust at south pole. The similarity between black carbon and dust suggests that the seasonality may be primarily due to common transport of a continental aerosol to Antarctica, although one expects some differences due to different location of the sources. The Antarctic atmosphere is fed by exchanges with surrounding air masses and this exchange is linked to the overall vigor of the transport from low latitude regions. Long-range transport of continental aerosol is generally achieved in the upper troposphere. We would expect enhanced transport into Antarctica during the summer months when the circumpolar vortex (whose influence extends from the stratosphere down to about $5 \mathrm{~km}$ ) breaks down and surface inversions are weaker [König-Langlo et al., this issue]. While this explanation can partly account for a summer maximum, it would not easily explain a doublet, or a maximum in October, when the vortex is still well-developed in most years. It has been shown, however, that in spring at coastal sites, the arrival of warm air from the seaward direction was generally accompanied by significant enhancement of continental markers such as radon, $\mathbf{B C}$, or dust [Picciotto and Wilgain, 1963; Polian et al., 1986]. This shows that even in spring, transport of continental air to coastal Antarctica is possible, even if not as favored as in summer.

From these considerations, it appears that transport variability alone can account for the observed $\mathrm{BC}$ variability and could be the major determinant for either the repetitive seasonal variability or the year-to-year variability (Figure 5).

4.1.2. Sources of black carbon to Antarctica. Discrepancies observed between BC and total aerosol concentration data in fall and during short episodes of warm air advection in continental Antarctica (Hogan et al., 1990) strongly suggest that source intensity is also modulating overall concentration levels. Although $\mathrm{BC}$ may be produced by either fossil fuel combustion or biomass burning, it may be assumed that the main source of atmospheric BC in the southern hemisphere and thus Antarctica is tropical biomass burning. All three continents (Africa, South America, and Australia) are severely affected by biomass burning [Levine, 1990], but owing to economic reasons and population pressure, most of 


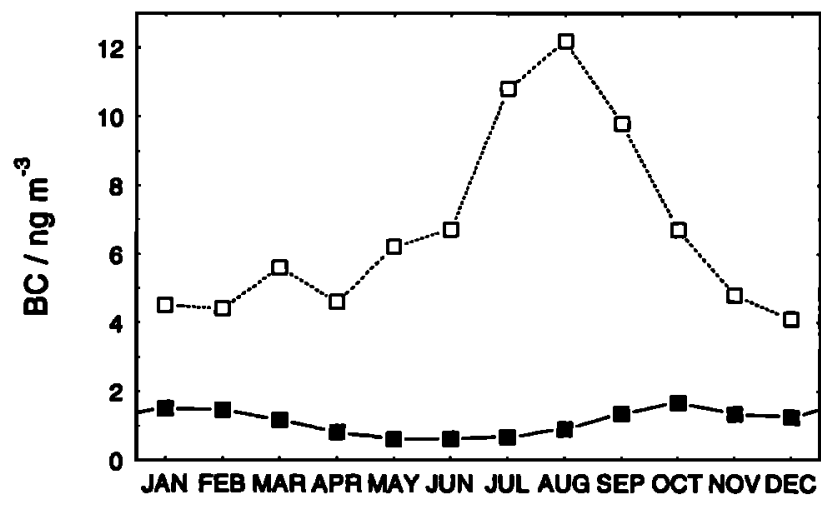

Figure 7. Four-year averaged seasonal cycle (based on the monthly logarithmic means of Figure 5) of BC at Halley (solid line), and the 3-year averaged seasonal cycle for Amsterdam Island (dashed line).

the burning occurs in Africa and South America, representing about $3400 \mathrm{Tg}$ of carbon emitted into the atmosphere, of which about $5 \mathrm{Tg}$ is emitted as $\mathrm{BC}$ aerosols.

Tropical biomass burning is characterized by a significant background of domestic and agricultural fires with overwhelming superimposition of bush fires and deforestation fires during the dry season [Crutzen and Andreae, 1990]. The seasonal fires release 8 to 10 times more carbon than regular fires. In the southern hemisphere, the dry season stretches up to 6 months from May to November. Atmospheric concentrations of several atmospheric species reflect the regional scale importance of the burning season as reported, for example, for ozone measurements [Fishman and Larsen, 1987] or BC aerosol records [Artaxo et al., 1994; Cachier et al., 1997]. At a given location, however, most fires occur in periods of less than 2 months, and a shift in the timing of intensive burning may be observed from one region to another. For savanna regions, the heart of the dry season may be observed approximately from July to October moving from the north to more southern regions. However, for forest fires in Amazonia, the peak of emissions occurs at the end of the dry season (November) due to the need for tree wood to dry before burning.

From these considerations, it may be seen that the period October to late November will be the most favorable with respect to global biomass burning source intensity. Coincidentally, the southernmost part of Africa is then in the fire season which is the most favourable situation for transport and inputs to Antarctica. It has been shown that biomass buming pollutants may be entrained in the general circulation [Garstang et al., 1997]. Dust uplift and entrainment would also be expected to be strongest during the dry season, leading to a similar seasonality.

It may be thus inferred that the occurence of BC (and dust) maxima in spring is due to the conjunction of the two factors, a strong source intensity and occasional favorable meteorology, whereas the extension of this maximum in summer is primarily due to a highly effective transport to Antarctic sites in this season.

\subsection{BC Transport at Different Subantarctic and Antarctic Sites}

BC data can be compared for south pole, Halley, Amsterdam Island $\left(77^{\circ} \mathrm{E}, 38^{\circ} \mathrm{S}\right)$, and Lamto, a savanna site in Africa. As previously mentioned, the savanna site concentrations reflect the regional background of biomass buming with overwhelming inputs during the heart of the dry season [Cachier et al., 1997]. The same phenomenon is observed at Amsterdam Island where the coincidence of the fire season and efficient transport from the
Table 1. BC Concentrations for Four Sites With Decreasing Latitude

\begin{tabular}{lcccc}
\hline & Mean & Minimum & Maximum & $\begin{array}{c}\text { Maximum/ } \\
\text { Minimum }\end{array}$ \\
\hline South pole & 0.6 & 0.3 & 1.5 & 5 \\
Halley & 1 & 0.6 & 1.7 & 3 \\
Amsterdam Island & 8 & 3.5 & 21.5 & 6 \\
Lamto & 1500 & 500 & 5000 & 10 \\
\hline
\end{tabular}

Annual and extrema monthly means are in $\mathrm{ng} \mathrm{m}^{-3}$

southern African continent (as attested by Rn measurements) favor a major enhancement of concentrations in late austral summer (Figure 7). At this site the major importance of transport over source intensity has been pointed out [Cachier et al., 1997].

The two Antarctic sites (Halley and south pole) display the same seasonality for BC concentrations, a seasonality which is nearly in antiphase with source intensity. Maximum concentration levels in each austral spring and summer thus primarily reflect the composition of the hemispheric background of tropical domestic fires. The different seasonality between sites confirms the major importance of transport and of the breakdown of the polar vortex for continental inputs to the Antarctic atmosphere.

From Table 1, it may be seen that there is only 1 order of magnitude (or less) difference of concentrations between Antarctic and subantarctic sites, whereas the concentration drop from savanna source regions is nearly 3 orders of magnitudes. This could indicate that major losses of combustion aerosols by in-cloud scavenging or atmospheric dilution occur rapidly over the continents. Noteworthy is the fact that the ratios of maxima to minima for monthly means are similar for the four sites suggesting a mutual balance between the three determinants for BC concentrations: wet scavenging and source intensity in the source region, transport and source intensity at subantarctic and Antarctic sites.

The data for black carbon can be compared to measurements of other species believed to be ot biomass burning origin. The seasonal cycle of light hydrocarbons and particularly acetylene at Neumayer shows a marked seasonality with a max/min ratio value of 3, very similar to that observed for $\mathrm{BC}$ at Halley. However, the peak appears in late winter/spring, centered on September which is more or less in agreement with the biomass burning season but displays a significant shift by comparison with aerosol data. This discrepancy is at first puzzling, but an explanation could lie in the

Table 2. $\mathrm{C}_{2} \mathrm{H}_{2} / \mathrm{BC}$ Ratio

\begin{tabular}{lllll}
\hline & Maximum & \multicolumn{3}{c}{ Minimum } \\
\hline $\begin{array}{l}\text { Antarctic } \\
\text { (Neumayer/Halley) }\end{array}$ & $30 / 1.7$ & $(18)$ & $8 / 0.6$ & $(13)$ \\
Amsterdam Island & $200 / 21$ & $(10)$ & $30 / 3.5$ & $(8.5)$ \\
Lanto & $600 / 5000$ & $(0.12)$ & & \\
\hline
\end{tabular}

Acetylene data are from Rudolph et al. [1992] for Neumayer and Bonsang et al. [1995] and B. Bonsang (personal communication, 1997)for other sites. Values are monthly means. Acetylene is in ppt, $\mathrm{BC}$ is in $\mathbf{n g ~ m}^{-3}$, ratio in parentheses. 


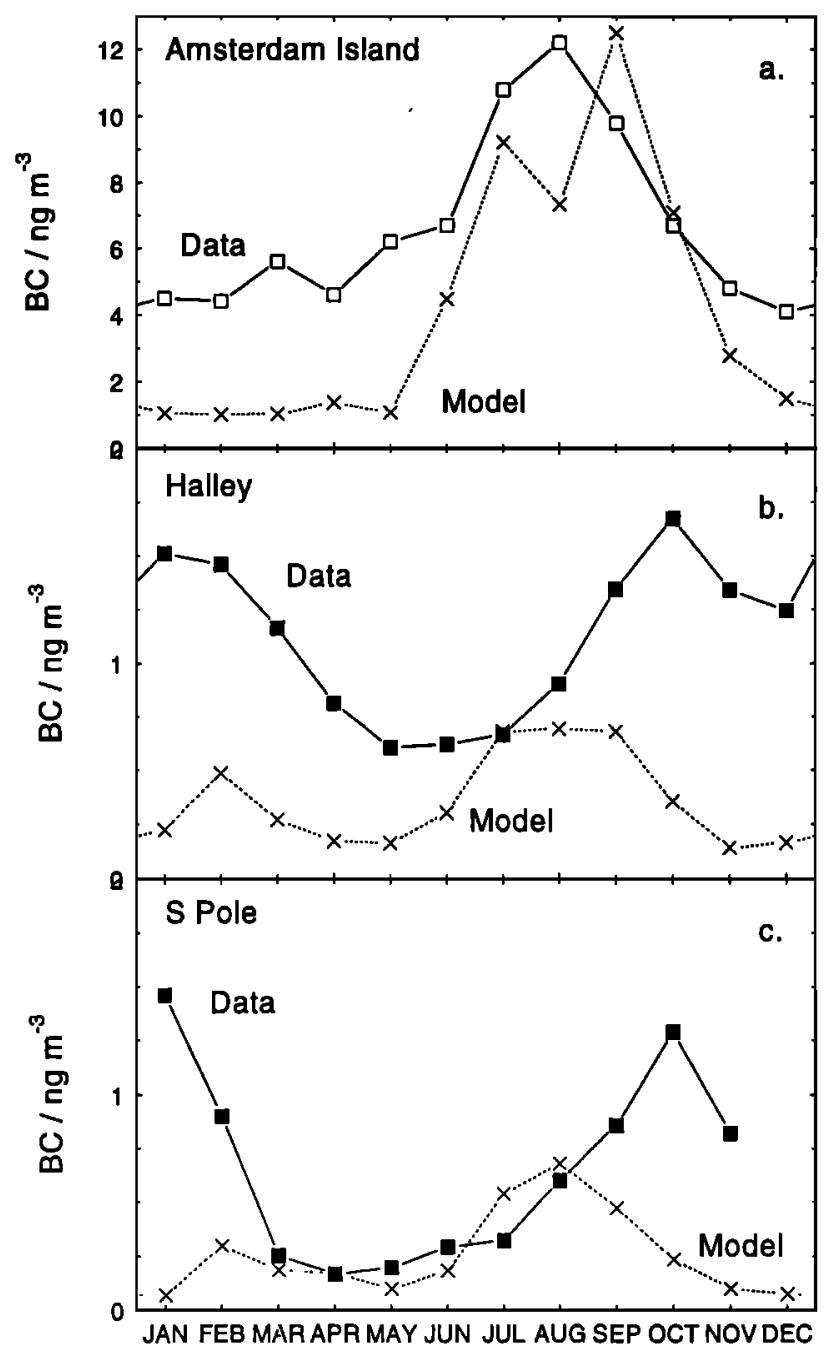

Figure 8. Measured $B C$ concentrations (solid lines) and model output (dashed lines) for (a) Amsterdam Island, (b) Halley, and (c) south pole.

fact that high temperature savanna and forest fires are much better emitters of acetylene than domestic fires; if so, the favorable opening of polar vortex after the bush fire season would be of little relevance for acetylene transport to the Antarctic atmosphere. This is not the case for $\mathrm{BC}$ aerosols which are comparatively more abundant in domestic fire than in intense fire plumes [Cachier et al., 1997].

From the acetylene to $\mathrm{BC}$ concentration ratios shown in Table 2 , the atmospheric behavior of $\mathrm{BC}$ and acetylene differs strikingly in accordance with their mean residence time: acetylene getting relatively more abundant far from source regions. Differences in atmospheric pathways are, here too, more important during the first days of life over or close to continental source regions.

\subsection{Modeling Transport of BC Aerosols}

A global three-dimensional (3-D) Lagrangian model (Grantour model from Lawrence Livermore National Laboratory, U.S.A.) has been used for the study of BC transport to Amsterdam Island and a few selected Antarctic sites [Liousse et al., 1996]. This off-line model has a spatial resolution of $4.5^{\circ}$ latitude by $7.5^{\circ}$ longitude and 12 vertical levels, and the number of air parcels used $(50,000)$ is optimized for obtaining monthly means. Comparison with the experimental record of $\mathrm{BC}$ which is assumed to be inert in the atmosphere may give interesting indications on valuable and/or weak characteristics of the model. Such a comparison may also shed light on the main determinants for $\mathrm{BC}$ aerosol concentrations at a given site.

At the Amsterdam Island location, the model and observations are in fairly good agreement (Figure 8a) demonstrating that the magnitude and seasonality of emissions in southern Africa at least are correctly represented in the model. For Antarctic sites, however (Figures 8b, 8c, and 9), a common feature is on average the underprediction of BC concentrations (especially for seasonal maxima), the discrepancy being still more pronouced in central Antarctica. The seasonality is also incorrect but primarily dictated by the timing of biomass burning. A small secondary maximum in summer in the model output represents the vortex breakdown. The strikingly poor comparison of experimental data sets against the model (Figure 8) points out an important problem of the model at high latitude which probably lies in a poor representation of advective transport toward Antarctica, which needs to be revisited in the future.

\section{Conclusion}

We have shown that it is possible to use detailed meteorological data to correct black carbon data containing many rather high incidences of local pollution. The local input is in fact a useful tracer for local contamination reaching other samples and has allowed us to verify that our major ion data are free from local effects.

The filtered $\mathrm{BC}$ data give values among the smallest reported in the world, less than a factor 2 higher than those recorded at south pole. The filtered BC data at Halley show a clear seasonal cycle, peaking in summer, but with an absolute maximum apparently in October. This is in good agreement with what has been seen at south pole (where levels are somewhat reduced) and matches rather well with the seasonality of dust at Neumayer. Since the source of

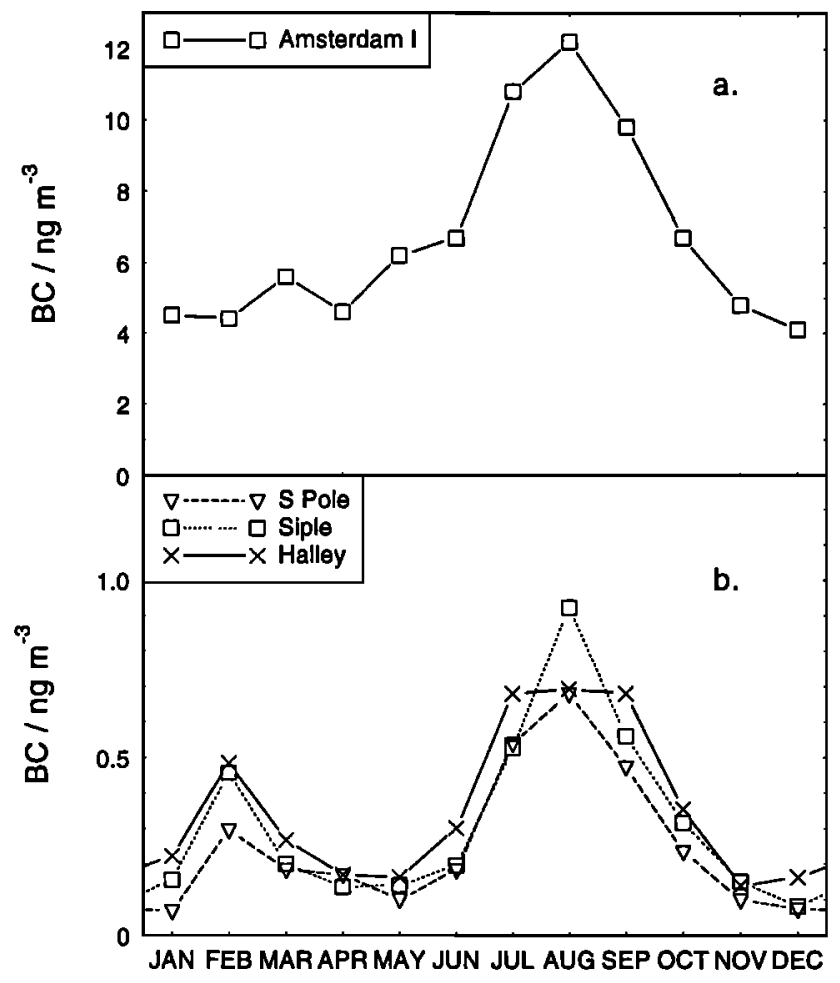

Figure 9. Modeled $B C$ concentrations for (a) Amsterdam Island and (b) three Antarctic sites. Note the large scale change between Figures $9 \mathrm{a}$ and $9 \mathrm{~b}$. 
$\mathrm{BC}$ is almost certainly tropical biomass burning which in the southern hemisphere has a seasonality different from that of the Halley BC signal, we infer that BC concentrations must be strongly modulated by the efficiency of transport to Antarctica. Better understanding of the transport seasonality is required and will be reached through estimating back trajectories from sampling sites [Kottmeier and Fay, this issue], and from running models with realistic transport.

Nonetheless, the similarity of the signals from Halley and south pole, a coastal and inland site, suggests that there is a rather common Antarctic-wide signal that originates in the biomass burning areas of the world. Although calculations have not been carried out, by analogy with earlier calculations [Warren and Clarke, 1990; Bodhaine, 1995], we can estimate that the radiative effect of these concentrations in the atmosphere, as well as their effect on the albedo of surface snow, must be very small. Only within a few hundred meters of the station would higher values of $\mathrm{BC}$ (leading to lower albedos) be expected at times. This finding probably applies to the entire Antarctic continent outside the immediate vicinity of stations.

The biomass buming source is mostly located in tropical areas. Particularly during the last decade (1981-1990), this source has been subjected to an important increase due to greater deforestation, savanna fire turnover, or fuelwood use by an increasing population. If long-term meteorological transport variability is small, the source enhancement should appear in longterm atmospheric concentration records. As shown in this work, $\mathrm{BC}$ and acetylene data along with the observation of other tracers could give a quantitative indication of the global increase of the various components of biomass burning. A significant increase of a few percent per year has already been observed for light hydrocarbons [Rudolph et al., 1992]. Up to now, the BC record is, however, too short to delineate any change. Ice core records, assuming they are representative of the atmosphere above them [Wolff et al., this issue (b)], offer the possibility of extending observations back in time. BC in ice is a proxy of combustions owing to its unambiguous origin and chemical inertia. Recent and detailed work in Greenland ice (M.H. Pertuisot et al., manuscript in preparation, 1997) has proved that BC from biomass burning is satisfactorily incorporated in snow and ice and closely records fluctuations of the regional and hemispheric biomass burning source. The similarity of the atmospheric signal in coastal and central Antarctica implies that ice core sites in Antarctica may give rather representative records of past variations in biomass buming in the southern hemisphere.

Acknowledgments. We thank the many personnel at Halley who have looked after the aethalometer over the past 4 years. Cathy Liousse kindly provided model output.

\section{References}

Artaxo, P., M. L. C. Rabello, W. Maenhaut, and R. van Grieken, Trace elements and individual particle analysis of atmospheric aerosols from the Antarctic peninsula, Tellus, Ser. B, 44, 318334, 1992.

Artaxo, P., F. Gerab, M. A. Yamasoe, and J. V. Martins, Fine mode aerosol composition at three long-term atmospheric monitoring sites in the Amazon Basin, J. Geophys. Res., 99, 22857-22868, 1994.

Bodhaine, B. A., Aerosol absorption measurements at Barrow, Mauna Loa, and the south pole, J. Geophys. Res., 100, 8967$8975,1995$.

Bonsang, B., C. Boissard, M. F. LeCloarec, J. Rudolph, and J. P.
Lacaux, Methane, carbon monoxide and light non-methane hydrocarbon emissions from African burnings during the FOSDECAFE experiment, I. Atmos. Chem., 22, 149-162, 1995.

Cachier, H., Combustion carbonaceous aerosols in the atmosphere: Implications for ice core studies, in Ice Core Studies of Global Biogeochemical Cycles, NATO ASI Ser. I, vol. 30, edited by R. J. Delmas, pp. 313-346, Springer-Verlag, New York, 1995.

Cachier, H., C. Liousse, M. H. Pertuisot, A. Gaudichet, F. Echalar, and J. P. Lacaux, African fire particulate emissions and atmospheric influence, in Biomass Burning and Global Change, edited by J. S. Levine, pp. 428-440, MIT Press, Cambridge, Mass., 1997.

Chylek, P., B. Johnson, and H. Wu, Black carbon concentration in Byrd Station ice core: From 13,000 to 700 years before present, Ann. Geophys., 10, 625-629, 1992.

Chylek, P., G. Videen, D. Ngo, R. G. Pinnick, and J. D. Klett, Effect of black carbon on the optical properties and climate forcing of sulfate aerosols, J. Geophys. Res., 100, 16325-16332, 1995.

Crutzen, P. J., and M. O. Andreae, Biomass burning in the tropics: Impact on atmospheric chemistry and biogeochemical cycles, Science, 250, 1669-1678, 1990.

Fishman, J., and J. C. Larsen, Distribution of total ozone and stratospheric ozone in the tropics: Implications for the distribution of tropospheric ozone, J. Geophys. Res., 92, 66276632, 1987.

Garstang, M., P. D. Tyson, H. Cachier, and J. P. Lacaux, Atmospheric transports of particulate and gaseous products by fires, in Sediment Records of Biomass Burning and Global Change, NATO ASI Series I, vol. 51, edited by J. S. Clark et al., Springer-Verlag, New York, 1997.

Hansen, A. D. A., B. A. Bodhaine, E. G. Dutton, and R. C. Schnell, Aerosol black carbon measurements at the south pole: Initial results, 1986-1987, Geophys. Res. Lett., 15, 1193-1196, 1988.

Hogan, A. W., W. G. Egan, J. A. Samson, S. C. Barnard, D. M. Riley, and B. B. Murphy, Seasonal variation of some constituents of Antarctic tropospheric air, Geophys. Res. Lett., 17, 2365-2368, 1990.

Jaenicke, R., V. Dreiling, E. Lehmann, P. K. Koutsenoguii, and J. Stingl, Condensation nuclei at the German Antarctic station "Georg von Neumayer," Tellus, Ser. B, 44, 311-317, 1992.

König-Langlo, G., J. King, and P. Pettre, Climatology of the three coastal Antarctic stations Dumont d'Urville, Neumayer, and Halley, J. Geophys. Res., this issue.

Kottmeier, C., and B. Fay, Trajectories in the Antarctic lower troposphere, J. Geophys. Res., this issue.

Legrand, M., M. de Angelis, H. Cachier, and A. Gaudichet, Boreal biomass burning over the last 80 years recorded in a SummitGreenland ice core, in Ice Core Studies of Global Biogeochemical Cycles, NATO ASI Series I, vol. 30, edited by R. J. Delmas, pp. 347-360, Springer-Verlag, New York, 1995.

Levine, J. S., Global biomass burning: atmospheric, climatic and biospheric implications, Eos Trans. AGU, 71, 37, 1990.

Liousse, C., H. Cachier, and S. G. Jennings, Optical and thermal measurements of black carbon aerosol content in different environments: Variation of the specific attenuation cross-

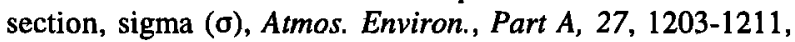
1993.

Liousse, C., J. E. Penner, C. Chuang, J. J. Walton, H. Eddleman, and $\mathrm{H}$. Cachier, A global three-dimensional model study of carbonaceous aerosols, J. Geophys. Res., 101, 19411-19432, 1996.

Minikin, A., M. Legrand, J. S Hall, D. Wagenbach, C. Kleefeld, E. W. Wolff, E. Pasteur, and F. Ducroz, Sulfur-containing species 
(sulfate and MSA) in coastal Anțarctic aerosol and precipitation, J. Geophys. Res., this issue.

Picciotto, E., and S. Wilgain, Fission products in Antarctic snow, a reference level for measuring accumulation, J. Geophys. Res., 68, 5965-5972, 1963.

Polian, G., G. Lambert, B. Ardouin, and A. Jegou, Long-range transport of continental radon in subantarctic and Antarctic areas, Tellus, Ser. B, 38, 178-189, 1986.

Rudolph, J., A. Khedim, T. Clarkson, and D. Wagenbach, Longterm measurements of light alkanes and acetylene in the Antarctic troposphere, Tellus, Ser. B, 44, 252-261, 1992.

Wagenbach, D., Coastal Antarctica: Atmospheric chemical composition and atmospheric transport, in Chemical Exchange Between the Atmosphere and Polar Snow, NATO ASI Ser. I, vol. 43, edited by E. W. Wolff, and R. C. Bales, pp. 173-199, Springer-Verlag, New York, 1996.

Wagenbach, D., F. Ducroz, R. Mulvaney, L. Keck, A. Minikin, M. Legrand, J. S. Hall, and E. W. Wolff, Sea-salt aerosol in coastal Antarctic regions, J. Geophys. Res., this issue.

Warren, S. G., and A. D. Clarke, Soot in the atmosphere and snow surface of Antarctica, J. Geophys. Res., 95, 1811-1816, 1990.
Wolff, E. W., M. R. Legrand, and D. Wagenbach, Coastal Antarctic aerosol and snowfall chemistry, J. Geophys. Res., this issue (a).

Wolff, E. W., J. S. Hall, R. Mulvaney, E. Pasteur, D. Wagenbach, and M. Legrand, Relationship between the chemistry of air, fresh snow and firn cores for aerosol species in coastal Antarctica, J. Geophys. Res., this issue (b).

H. Cachier, Centre des Faibles Radioactivités, Laboratoire Mixte CNRS-Commissariat à l'Ene'igie Atomique, Avenue de la Terrasse, 91198 Gif sur Yvette, France. (e-mail: helene.cachier@cfr.cnrs-gif.fr)

E. W. Wolff, British Antarctic Survey, High Cross, Madingley Road, Cambridge CB3 0ET, England. (e-mail: e.wolff@bas.ac.uk)

(Received January 21, 1997; revised April 30, 1997;

accepted May 1, 1997.) 